\title{
Differences in cancer characteristics of Chinese patients with prostate cancer who present with different symptoms
}

\author{
Samson YS Chan, CF Ng *, Kim WM Lee, CH Yee, Peter KF Chiu, Jeremy YC Teoh, Simon SM Hou
}

This article was published on 9 Dec 2016 at www.hkmj.org.

\section{A B S T R A C T}

Introduction: Currently there is no structured prostate cancer screening programme in Asia. Early diagnosis of prostate cancer in Asia is by an opportunistic case-finding approach, that is, offering prostate-specific antigen testing to an individual without obvious symptoms of prostate cancer. In this study, we investigated the relationship between the mode of presentation and the characteristics of prostate cancers diagnosed in our hospital.

Methods: We recruited 120 consecutive Chinese patients with prostate cancer newly diagnosed from September 2011 to February 2013 in a regional hospital in Hong Kong. Patient demographics, symptoms, presentation, staging, and risk profiles were collected and analysed.

Results: The number of subjects diagnosed during a health check (group 1), investigated for symptoms with no/low suspicion of prostate cancer (group 2), investigated for symptoms where prostate cancer was suspected (group 3), or who had undergone transurethral prostatectomy (group 4) were 12 (10.0\%), 53 (44.2\%), 46 (38.3\%), and nine (7.5\%), respectively. Overall mean age was 71.0 (range, 54-90) years, and patients in group 3 were significantly older than those in groups 1 and $2 \quad(\mathrm{P}<0.001)$. Patients in group 3 had a significantly higher level of serum prostate-specific antigen, higher incidence of abnormal digital rectal examination, and more metastatic disease at presentation than the other groups. Nonetheless, more than $50 \%$ of the prostate cancers in groups 1 and 2 were of intermediate risk or higher staging at presentation. After a median follow-up of 32 months, cancer-specific survival was $100 \%$ for each of groups 1, 2, and 4 but was only $76.8 \%$ for group $3(\mathrm{P}=0.006)$.

Conclusions: Patients with prostate cancer who presented with prostate cancer-related symptoms had more metastatic disease and poorer survival than patients diagnosed by a case-finding approach. Moreover, more than half of those patients diagnosed by case finding belonged to intermediateor higher-risk groups for which active treatment was recommended.

Hong Kong Med J 2017;23:6-12

DOI: 10.12809/hkmj164875

SYS Chan, MB, ChB, MRCS

CF Ng ${ }^{*}, M D$, FRCSEd (Urol)

KWM Lee, BSc, MPH

CH Yee, MB, BS, FRCSEd (Urol)

PKF Chiu, MB, ChB, FRCSEd (Urol)

JYC Teoh, MB, BS, FRCSEd (Urol)

SSM Hou, MB, BS, FHKAM (Surgery)

SH Ho Urology Centre, Division of Urology, Department of Surgery, The Chinese University of Hong Kong, Prince of Wales Hospital, Shatin, Hong Kong

* Corresponding author: ngcf@surgery.cuhk.edu.hk

New knowledge added by this study

- In the local Chinese population, patients with prostate cancer who presented with prostate cancer-related symptoms had more metastatic disease and poorer survival than asymptomatic patients.

- More than half of those patients with prostate cancer diagnosed by prostate-specific antigen (PSA) testing (case-finding approach) had intermediate- or higher-risk disease warranting treatment.

Implications for clinical practice or policy

- Health care professionals could offer PSA testing to appropriate male patients when they are seen for nonprostate-cancer-related symptoms after appropriate counselling. This may help to improve outcome and survival of prostate cancer patients.

\section{Introduction}

Prostate cancer is the second most frequently diagnosed cancer of men worldwide, with the highest incidence and prevalence rates occurring in more developed societies. ${ }^{1}$ The incidence of prostate cancer is also increasing in Asian countries. ${ }^{2}$ Many reasons have contributed to this recent rise in incidence in Asia, including the increase in the ageing population, the westernised diet, and also the increased use of serum prostate-specific antigen (PSA) for cancer detection. ${ }^{3,4}$ Although current evidence supports the use of PSA testing to decrease 
the incidence of metastatic disease and prostate cancer-specific mortality, ${ }^{5}$ the use of serum PSA for the early detection of prostate cancer is still controversial. $^{6,7}$ One of the concerns is the risk of overdiagnosis and overtreatment of low-risk cancer that may result in more potential harm than benefit to patients. ${ }^{8-10}$ There are many types of prostate cancer screening approaches. Currently, there is no structured prostate cancer screening programme in Asia. Therefore, early diagnosis of prostate cancer in Asia is by an opportunistic case-finding approach, that is, offering PSA testing to an individual without obvious signs and symptoms of prostate cancer. Information on the characteristics of prostate cancer diagnosed by various approaches in Asia is lacking, however. We postulated that patients diagnosed by a case-finding approach, such as during a routine health check or a consultation for symptoms with a low suspicion of prostate cancer origin, would have a better prognosis than those who presented with symptoms related to prostate cancer, with or without metastatic disease. We investigated the relationship between the mode of presentation and the characteristics of prostate cancers diagnosed in our hospital.

\section{Methods}

This was a prospective cohort study to assess consecutive adult male patients diagnosed with prostate cancer at Prince of Wales Hospital, a regional hospital in Hong Kong, between September 2011 and February 2013. Institutional ethics approval was obtained for the study. Informed consent was obtained from all study subjects prior to enrolment in the study.

All patients aged 18 years or above at our hospital with histological confirmation of prostate cancer were identified and approached for inclusion in this study. After informed consent was obtained, information on the initial presentation of the patient's condition, prostate cancer characteristics at diagnosis, and the initial treatment plan were collected. Patients were then followed up for a minimum of 2 years, and the clinical outcome was assessed. All cancer was graded using the Gleason grading system that is based on the histological pattern of the cancer tissue. The tissue was graded from 1 (well-differentiated) to 5 (poorly differentiated). Each biopsy was given two scores, the first indicated the most common pattern and the second, the highest grading. ${ }^{11}$ Our scoring system for prostate cancer consists of staging according to TNM staging $2010^{12}$ and risk stratification according to the National Comprehensive Cancer Network (NCCN) guideline. ${ }^{13}$

Subjects were divided into four groups according to the initial clinical presentation of their prostate cancer by two investigators who were

\section{出現不同症狀的前列腺癌華籍患者的癌症 特徵差異}

陳旭新、吳志輝、李慧敏、余知行、趙家鋒、張源津、侯仕明

引言：亞洲尚未有前列腺癌篩查計劃, 目前主要是透過機會性病例篩 檢方式作早期診斷, 意謂向沒有明顯前列腺癌症狀的人提供前列腺特 異性抗原（PSA）測試。本研究旨在探討本院前列腺癌患者疾病表現 模式和前列腺癌特點之間的關係。

方法：我們於 2011 年9月至2013年2月期間招募了 120 位新確診前列 腺癌的華籍患者, 收集並分析病人的特徵、症狀、癌病分期和風險因 素。

結果：病人分為四組：第一組是於常規健康檢查期間被診斷前列腺 癌的病人（12例， $10.0 \%)$; 第二組是因症狀與前列腺癌無關或低 關係而求診的病人（53例，44.2\%）；第三組是因與前列腺癌相關症 狀而求診的病人 $(46$ 例, $38.3 \%)$; 第四組是因接受經尿道切除前 列腺術而確診前列腺癌的病人（9例， $7.5 \%$ )。病人平均年齡 71.0 歲 （介乎54-90歲）。第三組病人明顯比第一、二組年長（ $\mathrm{P}<0.001 ）$ 與其他組別比較, 第三組病人的血清PSA水平較高, 肛門指診有異常 結果以及就診時發現有轉移性疾病的情況較多。第一、二組病人中超 過 50\%就診時發現的前列腺癌均屬於中度風險或以上階段。經過 32 個 月的中位隨訪後，第一、二、四組與前列腺癌相關的存活率均為 $100 \%$ ，第三組只有76.8\%（ $\mathrm{P}=0.006 ）$

結論：相比於健康檢查時確診或是因非前列腺癌相關症狀求診而確診 的患者, 確診時已經有前列腺癌相關症狀的患者有更多擴散性疾病和 較低存活率。此外, 超過一半透過機會性病例節檢而確診的患者屬於 中 / 高風險群組, 需接受積極治療。

blinded to the clinical outcome during the assessment and then confirmed by a senior investigator. Any discrepancy was discussed and a final allocation made. The health check group (group 1) included patients in whom a raised PSA was detected during a routine health check. Group 2 comprised patients diagnosed with prostate cancer by the case-finding approach after they presented with symptoms with no/low clinical suspicion of prostate cancer (eg renal cysts, non-specific abdominal pain). Group 3 comprised patients with a high clinical suspicion of prostate cancer or malignant disease, for example, lower urinary tract symptoms with abnormal digital rectal examination (DRE), bone pain, or weight loss. Finally, those patients with a histological diagnosis of prostate cancer made following transurethral resection of the prostate (TURP) but with no preoperative suspicion of prostate cancer were assigned to the TURP group (group 4).

Since prostate cancer arises mostly from the peripheral zone (in contrast to benign prostate hyperplasia $[\mathrm{BPH}]$ that commonly arises from the transition zone), patients with early-stage prostate cancer are usually asymptomatic. ${ }^{14}$ Not until the tumour becomes locally advanced (with clinical signs of abnormal DRE) do patients have voiding 
symptoms attributed to prostate cancer. Therefore, in a patient who presents with lower urinary tract symptoms (LUTS) and normal DRE, the symptoms are more likely related to $\mathrm{BPH}$, not secondary to prostate cancer. Testing of PSA is not routine for male patients with LUTS. ${ }^{15,16}$ According to the Guidelines from the European Association of Urology, PSA measurement should only be performed to assess the risk of progression of LUTS or if a diagnosis of prostate cancer would change disease management. ${ }^{16}$ For patients who present with LUTS but with a low clinical suspicion of prostate cancer (ie normal DRE), PSA testing is considered case-finding for prostate cancer. In this study, such patients were assigned to group 2. This also applied to other presenting symptoms with no or low suspicion of being related to prostate cancer. Nonetheless, in subjects with LUTS and clinical symptoms or signs suspected to be secondary to prostate cancer, such as abnormal DRE findings, PSA testing would be part of the diagnostic process for prostate cancer, not case-finding. As a result, these patients would be assigned to group 3 .

After all data were collected, descriptive statistics were applied. A Chi squared test or Fisher's exact test was used to determine any relationship between the categorical outcome measures. Analysis of variance or Kruskal-Wallis test was used for normal or skewed data, and then followed by posthoc comparisons with Bonferroni adjustment. Kaplan-Meier survival analysis was applied to analyse survival among the four groups. Data management and analysis were performed using the Statistical Package for the Social Sciences (Windows version 22.0; SPSS Inc, Chicago [IL], US). A two-tailed test was used with significance set at $\mathrm{P}<0.05$.

\section{Results}

From September 2011 to February 2013, 126 consecutive patients with newly diagnosed, histologically confirmed prostate cancer were managed in our centre. One patient refused to participate in this study, and five patients were not capable of providing informed consent. Therefore 120 patients were enrolled in this study: group $1(n=12)$, group $2(n=53)$, group $3(n=46)$, and group $4(n=9)$ [Table 1]. The initial presenting symptoms of patients in groups 2 and 3 are listed in Table 2. In group 2, 43 patients presented with LUTS (including three with acute urinary retention) with low clinical suspicion of prostate cancer. Ten patients presented with other symptoms - seven with other urological symptoms and three with other general surgical problems. Among them, three patients (one with loin pain, one with erectile dysfunction, and one with hernia) were found to have abnormal DRE during consultation. In group 3, 33 patients presented with LUTS (nine patients with acute urinary retention) and abnormal DRE. Three patients presented with haematuria and DRE during initial workup was abnormal and a subsequent diagnosis was made of prostate cancer. Nine patients presented with metastatic symptoms, eg bone pain, acute spinal cord compression, and abnormal soft tissue mass. One patient presented with weight loss and was subsequently diagnosed to have non-metastatic prostate cancer (Table 2).

The overall mean age was 71.0 (range, 54-90) years (Table 1). Age and serum PSA level were statistically significantly different across groups. Multiple comparisons with Bonferroni correction revealed that patients in group 3 were significantly older than those in groups 1 and $2(\mathrm{P}<0.001)$. Patients

TABLE I. Demographics and cancer-related characteristics

\begin{tabular}{|c|c|c|c|c|c|c|}
\hline & \multicolumn{5}{|c|}{ No., No. (\%), or mean \pm standard deviation (range) } & \multirow[t]{2}{*}{ P value* } \\
\hline & Overall & Group 1 & Group 2 & Group 3 & Group 4 & \\
\hline No. of patients & 120 & $12(10.0)$ & $53(44.2)$ & $46(38.3)$ & $9(7.5)$ & - \\
\hline Age (years) & $71.0 \pm 8.1(54-90)$ & $65.3 \pm 8.8(56-85)$ & $68.8 \pm 6.4(54-84)$ & $75.2 \pm 8.1(54-90)$ & $70.8 \pm 7.2(62-82)$ & $<0.001$ \\
\hline Abnormal DRE & $44(36.7)$ & 0 & $3(5.7)$ & $41(89.1)$ & 0 & $<0.001$ \\
\hline Serum PSA level & $\begin{array}{c}116.51 \pm 395.51 \\
(0.8-3438.0)\end{array}$ & $\begin{array}{c}19.55 \pm 36.05 \\
(4.2-133)\end{array}$ & $\begin{array}{c}21.40 \pm 43.32 \\
(4.2-285)\end{array}$ & $\begin{array}{c}269.35 \pm 601.58 \\
\quad(54-3438.0)\end{array}$ & $\begin{array}{c}24.67 \pm 30.86 \\
(0.8-95.2)\end{array}$ & $<0.001$ \\
\hline Presence of metastasis & $30(25.0)$ & $1(8.3)$ & $4(7.5)$ & $24(52.2)$ & $1(11.1)$ & $<0.001$ \\
\hline Gleason sum $\geq 7$ & $55(45.8)$ & 7 (58.3) & $12(22.6)$ & $32(69.6)$ & $4(44.4)$ & $<0.001$ \\
\hline NCCN risk group & & & & & & - \\
\hline Very low/low† & $32(36.8)$ & $4(36.3)$ & $23(46.9)$ & $3(15.8)$ & $2(25.0)$ & \\
\hline Intermediate $†$ & $33(37.9)$ & 4 (36.3) & $15(30.6)$ & $11(57.9)$ & $3(37.5)$ & \\
\hline High† & $22(25.3)$ & $3(27.5)$ & $11(22.4)$ & $5(26.3)$ & $3(37.5)$ & \\
\hline Locally advanced & 3 & 0 & 0 & 3 & 0 & - \\
\hline Metastatic & 30 & 1 & 4 & 24 & 1 & - \\
\hline
\end{tabular}

Abbreviations: DRE = digital rectal examination; NCCN = National Comprehensive Cancer Network; PSA = prostate-specific antigen

* Comparison between the four groups

† Percentage was calculated for localised disease 
in group 3 also had a significantly higher serum PSA group $2(\mathrm{P}=0.045)$ by Kruskal-Wallis test. In group level compared with those in group $1(\mathrm{P}=0.044)$ and $3,41(89.1 \%)$ patients had an abnormal DRE $(\mathrm{P}<0.001)$.

With regard to disease status, the numbers

TABLE 2. Initial symptoms of patients in groups 2 and 3

\begin{tabular}{lcc}
\hline Symptom & Group 2 & Group 3 \\
\hline LUTS (including AUR) & 43 & 33 \\
Other urinary tract symptoms & & \\
$\quad$ Erectile dysfunction & 1 & - \\
$\quad$ Loin pain & 1 & - \\
\hline Haematuria & 3 & 3 \\
\hline Haemospermia & 1 & - \\
$\quad$ Renal cyst & 1 & - \\
\hline Other surgical problems & 3 & - \\
\hline Bone pain & - & 5 \\
\hline Acute spinal cord compression & - & 2 \\
\hline Soft tissue mass & - & 2 \\
Weight loss & - & 1 \\
\hline Total & $\mathbf{5 3}$ & $\mathbf{4 6}$ \\
\hline
\end{tabular}
of patients with a Gleason sum of $\geq 7$ were seven $(58.3 \%)$ in group $1,12(22.6 \%)$ in group 2,32 $(69.6 \%)$ in group 3 , and four $(44.4 \%)$ in group 4 . In accordance with the NCCN guideline, the number of patients with disease more severe than very low or low risk were eight $(66.7 \%)$ in group $1,30(56.6 \%)$ in group 2, $43(93.5 \%)$ in group 3, and seven $(77.8 \%)$ in group 4 (Table 1 ). In group 3, $24(52.2 \%)$ patients had metastatic disease at initial presentation, a much higher rate than in the other groups $(\mathrm{P}<0.001$, Fisher's exact test).

Since both groups 1 and 2 had no prostate cancer-related symptoms, we tried to combine the two groups to assess the characteristics of prostate cancer diagnosed by a case-finding approach. Group 3 patients had significantly older age, higher serum PSA level, more aggressive disease (Gleason sum $\geq 7$ ), and more metastatic disease at presentation than the combined groups 1 and 2 patients $(P<0.001$ for all parameters; Table 3).

TABLE 3. Comparison of the demographic and cancer-related characteristics of patients diagnosed by PSA testing (groups I and 2) and those who presented with symptoms (group 3)

\begin{tabular}{|c|c|c|c|}
\hline & \multicolumn{2}{|c|}{ Mean \pm standard deviation (range), No. (\%), or No. } & \multirow[t]{2}{*}{$P$ value } \\
\hline & Groups $1+2(n=65)$ & Group $3(n=46)$ & \\
\hline Age (years) & $68.1 \pm 6.9(54-85)$ & $75.2 \pm 8.1(54-90)$ & $<0.001$ \\
\hline Abnormal DRE & $3(4.6)$ & $41(89.1)$ & $<0.001$ \\
\hline Serum PSA level & $21.06 \pm 41.81(4.2-285)$ & $269.35 \pm 601.58(54-3438.0)$ & $<0.001$ \\
\hline Presence of metastasis & $5(7.7)$ & $24(52.2)$ & $<0.001$ \\
\hline Gleason sum $\geq 7$ & $19(29.2)$ & $32(69.6)$ & $<0.001$ \\
\hline \multicolumn{4}{|l|}{ NCCN risk group } \\
\hline Very low/low* & $27(45.0)$ & $3(15.8)$ & \\
\hline Intermediate* & $19(31.7)$ & $11(57.9)$ & \\
\hline $\mathrm{High}^{*}$ & $14(23.3)$ & $5(26.3)$ & \\
\hline Locally advanced & 0 & 3 & \\
\hline Metastatic & 5 & 24 & \\
\hline
\end{tabular}

Abbreviations: DRE = digital rectal examination; NCCN = National Comprehensive Cancer Network; PSA = prostate-specific antigen

* Percentage was calculated for localised disease

TABLE 4. Primary treatment in each patient group

\begin{tabular}{lcccc}
\hline Treatment & Group 1 $(\mathbf{n = 1 2})$ & Group 2 $(\mathbf{n = 5 3 )}$ & Group 3 (n=46) & Group 4 (n=9) \\
\hline No treatment & 1 & 5 & 4 & 6 \\
Radical surgery & 8 & 23 & 6 & 0 \\
Radical radiotherapy & 2 & 21 & 5 & 1 \\
Primary ADT & 1 & 3 & 26 & 2 \\
ADT + TURP & 0 & 1 & 5 & 0 \\
\hline
\end{tabular}

Abbreviations: ADT = androgen deprivation therapy; TURP = transurethral resection of the prostate

* Includes watchful waiting and active surveillance 


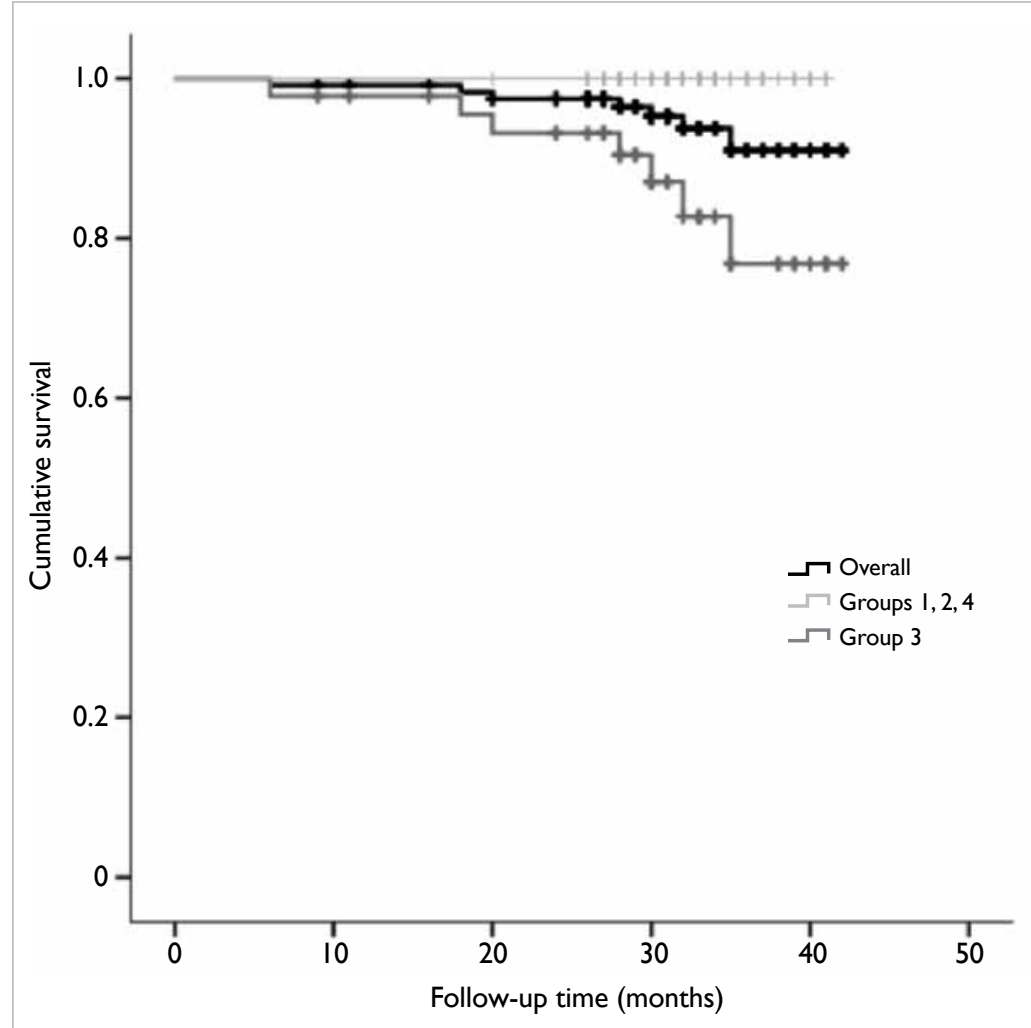

FIG. Cancer-specific survival for all and individual groups cohort was $91.0 \%$, but $100 \%$ for each of groups 1,2 , and 4 compared with only $76.8 \%$ for group 3 $(\mathrm{P}=0.006$, log-rank test; Fig).

\section{Discussion}

Since the introduction of PSA testing, there has been a worldwide change in the presentation of prostate cancer. More and more prostate cancers are diagnosed at a lower risk level and earlier stage for which curative treatment can be offered. ${ }^{17,18}$ As a result, the use of PSA testing for early detection of prostate cancer is believed to be one of the factors that has led to the decrease in overall prostate cancer mortality in many developed areas. ${ }^{2}$ From our cohort, we also observed that patients with prostate cancer diagnosed by case-finding approach using PSA testing (groups 1 and 2) had significantly more clinically localised disease and hence a higher chance of receiving curative-intent treatment than those patients who presented with prostate cancerrelated symptoms (group 3 ).

We also observed that the short-term cancerspecific mortality rate of patients who presented with prostate cancer-related symptoms (group 3) was significantly higher than that in the other groups. In our cohort, more than half of the patients in group 3 already had metastasis at diagnosis. Because patients presenting with metastasis have a much poorer outcome than other patients, ${ }^{19,20}$ it was not surprising that the mortality rate for patients who presented with symptoms was also higher. This indirectly supports the case-finding approach by PSA testing in patients with symptoms but no/low clinical suspicion of prostate cancer, as it might help to decrease the incidence of metastatic disease and hence the mortality related to prostate cancer. ${ }^{21}$

Although PSA testing is widely performed in western countries to detect early prostate cancer, its use in Asian countries is still not a common practice. From a population-based telephone survey involving 1002 Chinese men aged $\geq 50$ years in Hong Kong, only $9.5 \%$ had ever had a PSA test, and only $3.7 \%$ of the total sample had PSA test done during a routine health check. ${ }^{22}$ Even in more developed Asian countries such as Japan and South Korea, only 15\% to $20 \%$ of the population had had a PSA test. ${ }^{23}$ Only $10 \%$ of the prostate cancers in our cohort were diagnosed during a self-initiated health check with PSA testing. Therefore, offering a PSA test as case-finding for prostate cancer during a patient's consultation for non-prostate-cancer-related symptoms is an alternative approach for early detection of prostate cancer. We believe that this case-finding approach is feasible for the detection of early prostate cancer in our region, where public awareness and use of PSA testing is still low. Certainly, patients need to be well informed about the nature and implications of PSA testing before the test is performed. ${ }^{24,25}$ 
The main concerns surrounding the use of PSA testing for the detection of early prostate cancer are overdiagnosis and overtreatment. ${ }^{8-10}$ Only approximately $36 \%$ of patients in the study cohort had very low- or low-risk disease that might not require aggressive intervention. ${ }^{13,26}$ Even in those patients with prostate cancer diagnosed by PSA testing (ie groups 1 and 2 ), more than $50 \%$ were in the intermediate- or higher-risk groups. Testing of PSA level did help to detect patients with significantly high-risk prostate cancer that warranted further treatment. To minimise the risk of overtreatment, the Melbourne Consensus Statement advises uncoupling of the prostate cancer diagnosis from the intervention. ${ }^{5}$ Offering active surveillance to patients with low-risk disease will help to minimise the potential harm of overtreatment. In our cohort, for patients in groups 1 and 2 with very low- or lowrisk disease, six $(22.2 \%)$ opted for observation with no active treatment. We believe this concept should be promoted to both clinicians and patients, rather than limiting the use of PSA testing for the case finding of prostate cancer.

Currently, some newly proposed strategies, such as determination of the baseline PSA level earlier in $\operatorname{life}^{27,28}$ and the use of newer diagnostic tools, ${ }^{29,30}$ might help to reduce unnecessary prostatic biopsies and overdiagnosis of low-risk prostate cancer. Nonetheless, since most of these studies were conducted in Caucasian-based populations, further studies in Asian populations are necessary to verify their suitability in our region.

Although our data show that the short-term outcome of patients who present with prostate cancer-related symptoms seems to be worse than those diagnosed by PSA testing, this might be due to potential lead-time bias, that is, the increase in survival is actually due to the length of time between the detection of a disease by PSA testing and its usual clinical presentation and diagnosis. This will result in an increase in survival time for patients diagnosed by PSA testing. Other potential bias is length-time bias which suggests that annual PSA may only detect slow-growing tumours, that screening for prostate cancer does not detect the very tumour for which it is intended.

The aim of our study was not to assess the role of PSA testing in the detection of early prostate cancer or its effect on long-term outcome and survival of patients. Rather, we aimed only to compare cancer characteristics and short-term outcome among patients with different presentations. We also did not analyse the potential harm of PSA testing, prostatic biopsy, or morbidities related to treatment. The positive rate for prostatic biopsy depends on the level of serum PSA and DRE finding. From local experience, for patients with a normal DRE, the positive rate of prostatic biopsy for serum PSA level of $4-10 \mathrm{ng} / \mathrm{mL}$ and $10-20 \mathrm{ng} / \mathrm{mL}$ was only $6.7 \%$ $13.4 \%$ and $10.3 \%-21.8 \%$, respectively. ${ }^{31-33}$ Therefore, information on this would be helpful during patient counselling for prostatic biopsy. Another limitation of our study was the relatively small sample size from a single centre in Hong Kong, therefore our results might not represent the general situation in Hong Kong. Further studies, especially with multicentre collaboration, may help to confirm the applicability of our results in the local population.

\section{Conclusions}

Patients with prostate cancer presenting with related symptoms had more metastatic disease and poorer survival than those diagnosed by a case-finding approach using PSA testing during a health check or management of symptoms with a low suspicion of prostate cancer. More than half of the patients diagnosed by this case-finding approach belonged to intermediate- or higher-risk groups for which active treatment was recommended. Apart from a selfinitiated health check with PSA testing, offering PSA testing to appropriate patients who present with symptoms with no/low clinical suspicion of prostate cancer is an alternative approach to early diagnosis of prostate cancer. Pre-test counselling, including the discussion of potential bias (such as lead time or length-time bias), is essential. This may hopefully help to improve the short-term outcome for these patients.

\section{Declaration}

All authors have disclosed no conflicts of interest.

\section{References}

1. Torre LA, Bray F, Siegel RL, Ferlay J, Lortet-Tieulent J, Jemal A. Global cancer statistics, 2012. CA Cancer J Clin 2015;65:87-108.

2. Center MM, Jemal A, Lortet-Tieulent J, et al. International variation in prostate cancer incidence and mortality rates. Eur Urol 2012;61:1079-92.

3. Sim HG, Cheng CW. Changing demography of prostate cancer in Asia. Eur J Cancer 2005;41:834-45.

4. Pu YS, Chiang HS, Lin CC, Huang CY, Huang KH, Chen J. Changing trends of prostate cancer in Asia. Aging Male 2004;7:120-32.

5. Murphy DG, Ahlering T, Catalona WJ, et al. The Melbourne Consensus Statement on the early detection of prostate cancer. BJU Int 2014;113:186-8.

6. Schröder FH. Landmarks in prostate cancer screening. BJU Int 2012;110 Suppl 1:3-7.

7. Alberts AR, Schoots IG, Roobol MJ. Prostate-specific antigen-based prostate cancer screening: past and future. Int J Urol 2015;22:524-32.

8. Welch HG, Black WC. Overdiagnosis in cancer. J Natl Cancer Inst 2010;102:605-13.

9. Loeb S, Bjurlin MA, Nicholson J, et al. Overdiagnosis and overtreatment of prostate cancer. Eur Urol 2014;65:104655. 
10. Stone NN, Crawford ED. To screen or not to screen: the prostate cancer dilemma. Asian J Androl 2015;17:44-5.

11. Epstein JI. An update of the Gleason grading system. J Uro 2010;183:433-40.

12. Edge S, Byrd DR, Compton CC, Fitz AG, Greene FL, Trotti A. AJCC cancer staging manual. 7th ed. New York, NY: Springer; 2010.

13. National Comprehensive Cancer Network. NCCN Clinica Practice Guidelines in Oncology-Prostate cancer, version 1.2015. Available from: http://www.nccn.org. Accessed 1 Jul 2015.

14. Loeb S, Carter HB. Early detection, diagnosis, and staging of prostate cancer. In: Wein AJ, Kavoussi LR, Novick AC, et al, editors. Campbell-Walsh Urology. 10th ed. Philadelphia, PA: Elsevier Saunders; 2012: 2763-70.

15. European Association of Urology. Guidelines on the management of non-neurogenic male lower urinary tract symptoms (LUTS), incl. benign prostatic obstruction (BPO). Available from: http://uroweb.org/wp-content/ uploads/EAU-Guidelines-Non-Neurogenic-Male-LUTS LR.pdf. Accessed 1 Jul 2015.

16. Arianayagam M, Arianayagam R, Rashid P. Lower urinary tract symptoms-current management in older men. Aust Fam Physician 2011;40:758-67.

17. Cooperberg MR, Lubeck DP, Mehta SS, Carroll PR CaPSURE. Time trends in clinical risk stratification for prostate cancer: implications for outcomes (Data from CaPSURE). J Urol 2003;170(6 Pt 2):S21-7.

18. Crawford ED. Epidemiology of prostate cancer. Urology 2003;62(6 Suppl 1):3-12.

19. Chowdhury S, Robinson D, Cahill D, Rodriguez-Vida A, Holmberg L, Møller H. Causes of death in men with prostate cancer: an analysis of 50,000 men from the Thames Cancer Registry. BJU Int 2013;112:182-9.

20. Patrikidou A, Loriot Y, Eymard JC, et al. Who dies from prostate cancer? Prostate Cancer Prostatic Dis 2014;17:348-52.

21. Wu JN, Fish KM, Evans CP, Devere White RW, Dall'Era MA. No improvement noted in overall or cause-specific survival for men presenting with metastatic prostate cancer over a 20-year period. Cancer 2014;120:818-23.

22. So WK, Choi KC, Tang WP, et al. Uptake of prostate cancer screening and associated factors among Chinese men aged
50 or more: a population-based survey. Cancer Biol Med 2014;11:56-63.

23. Baade PD, Youlden DR, Cramb SM, Dunn J, Gardiner RA. Epidemiology of prostate cancer in the Asia-Pacific region. Prostate Int 2013;1:47-58.

24. Carter HB, Albertsen PC, Barry MJ, et al. Early detection of prostate cancer: AUA Guideline. J Urol 2013;190:419-26.

25. Basch E, Oliver TK, Vickers A, et al. Screening for prostate cancer with prostate-specific antigen testing: American Society of Clinical Oncology Provisional Clinical Opinion. J Clin Oncol 2012;30:3020-5.

26. European Association of Urology. Guidelines on prostate cancer. Available from: http://uroweb.org/wp-content/ uploads/09-Prostate-Cancer_LRV2-2015.pdf. Accessed 1 Jul 2015.

27. Lilja H, Cronin AM, Dahlin A, et al. Prediction of significant prostate cancer diagnosed 20 to 30 years later with a single measure of prostate-specific antigen at or before age 50 . Cancer 2011;117:1210-9.

28. Vickers AJ, Ulmert D, Sjoberg DD, et al. Strategy for detection of prostate cancer based on relation between prostate specific antigen at age 40-55 and long term risk of metastasis: case-control study. BMJ 2013;346:f2023.

29. Braun K, Sjoberg DD, Vickers AJ, Lilja H, Bjartell AS. A four-kallikrein panel predicts high-grade cancer on biopsy: independent validation in a community cohort. Eur Urol 2016;69:505-11.

30. Stattin P, Vickers AJ, Sjoberg DD, et al. Improving the specificity of screening for lethal prostate cancer using prostate-specific antigen and a panel of kallikrein markers: a nested case-control study. Eur Urol 2015;68:207-13.

31. Ng CF, Ng MT, Yip SK. Urology update 2-Management of uro-oncology and associated urological symptoms. Hong Kong Pract 2009;31:128-32.

32. Ng CF, Chiu PK, Lam NY, Lam HC, Lee KW, Hou SS. The Prostate Health Index in predicting initial prostate biopsy outcomes in Asian men with prostate-specific antigen levels of 4-10 ng/mL. Int Urol Nephrol 2014;46:711-7.

33. Teoh JY, Yuen SK, Tsu JH, et al. Prostate cancer detection upon transrectal ultrasound-guided biopsy in relation to digital rectal examination and prostate-specific antigen level: what to expect in the Chinese population? Asian J Androl 2015;17:821-5. 